\title{
Perinatal-Stress Induced Hyperinsulinism
}

National Cancer Institute

\section{Source}

National Cancer Institute. Perinatal-Stress Induced Hyperinsulinism. NCI Thesaurus.

Code C131277.

Transient hyperinsulinism that occurs in response to neonatal stress resulting in prolonged neonatal hypoglycemia, which is distinct from transitional hypoglycemia of typical infants. 